\title{
The Imperatives of Financial Instruments to Addressing the Working Capital Challenges of Businesses in the Global Value Chains Trades: The New World Trading Currency
}

\author{
Adeshile Adedeji Richard \\ The World Bank Open Learning Campus \\ Deji.adeshile@gmail.com
}

\begin{abstract}
:
The study was carried out to examine the level of awareness on financial instruments and familiarization with any other financial instruments apart from the Letter of Credit (L/C) and Bank Guarantee (BG). Furthermore, it examined the impacts of COVID-19 on business working capital and the level of readiness of the business to take advantage of financial instruments when fully innovated and globally acceptable. The study used primary data obtained through experience, observation, and opinion sampling from thirty businesses in Nigeria with digital market presence. Data were analyzed using a descriptive statistical method of Measures of frequency. From the study, an average respondent is aware of financial instruments application for financing their business working capital. However, very few are familiar with other financial instruments apart from L/C and BG. Unarguably, COVID-19 has impacted business working capital and many respondents are willing to take advantage of financial instruments when fully innovated and globally acceptable based on the principle of good faith amongst all actors in the GVCs trades. The recommendations include the need to embrace Global Registry of Financial Instruments (GRoFI) and encourage in-country and regional domestication by the Central Banks and

Multilateral Development Banks. Furthermore, the global and national leaders must embrace the Multilateral Committee on Financial Instruments (MultiCoFI) to work out the fine details to innovate financial instruments facilitating trade for development.
\end{abstract}

Keywords: Contract Enforcement; Economic Shared Prosperity; SDG-17; Emerging Market; Productivity 